\title{
Hypomethylating agents (HMA) for the treatment of acute myeloid leukemia and myelodysplastic syndromes: mechanisms of resistance and novel HMA-based therapies
}

\author{
Julia Stomper $\mathbb{B}^{1} \cdot$ John Charles Rotondo $\mathbb{I}^{1,2} \cdot$ Gabriele Greve ${ }^{1,3} \cdot$ Michael Lübbert $\mathbb{D}^{1,3}$
}

Received: 14 August 2020 / Revised: 1 February 2021 / Accepted: 4 March 2021 / Published online: 6 May 2021

(c) The Author(s) 2021. This article is published with open access

\begin{abstract}
Aberrant DNA methylation plays a pivotal role in tumor development and progression. DNA hypomethylating agents (HMA) constitute a class of drugs which are able to reverse DNA methylation, thereby triggering the re-programming of tumor cells. The first-generation HMA azacitidine and decitabine have now been in standard clinical use for some time, offering a valuable alternative to previous treatments in acute myeloid leukemia and myelodysplastic syndromes, so far particularly in older, medically non-fit patients. However, the longer we use these drugs, the more we are confronted with the (almost inevitable) development of resistance. This review provides insights into the mode of action of HMA, mechanisms of resistance to this treatment, and strategies to overcome HMA resistance including next-generation HMA and HMA-based combination therapies.
\end{abstract}

\section{Introduction}

Epigenetic modifications, such as DNA methylation represent an important therapeutic target in hematopoietic malignancies [1, 2]. DNA methylation occurs through the covalent addition of a methyl group to the $5^{\prime}$ carbon of the cytosine ring catalyzed by DNA methyltransferases (DNMT), resulting in 5-methylcytosine. There are three members of DNMT that have catalytic activity: DNMT1, DNMT3A, and DNMT3B. DNMT1 is the proposed maintenance methyltransferase that is responsible for copying DNA methylation patterns to the pre-existing hemimethylated post-replication DNA [3]. DNMT3A and DNMT3B are related proteins which establish DNA methylation patterns on unmethylated DNA functioning as

Michael Lübbert

michael.luebbert@uniklinik-freiburg.de

1 Department of Medicine I, Medical Center - University of Freiburg, Faculty of Medicine, University of Freiburg, Freiburg, Germany

2 Department of Medical Sciences, University of Ferrara, Ferrara, Italy

3 German Cancer Research Consortium (DKTK), Freiburg, Germany de novo methyltransferases [4]. The potential sites within the genome that can be methylated or demethylated are cytosine-guanine dinucleotides referred to as $\mathrm{CpG}$ dinucleotides. $\mathrm{CpG}$ islands are areas with a high concentration of $\mathrm{CpG}$.

In cancer, aberrant DNA methylation at $\mathrm{CpG}$ islands within promoter regions leads to the silencing of critical tumor suppressor genes involved in cancer-related pathways, such as invasion, DNA repair, and cell cycle regulation $[1,2]$.

\section{DNA hypomethylating agents}

The possibility to induce re-expression of silenced tumor suppressor genes and, in turn, stimulate tumor cells' reprogramming by reversing DNA methylation modifications, led to the pursuit of drugs with hypomethylating potential.

The first generation of DNA hypomethylating agents (HMA) was developed as conventional cytostatic therapy in the 1960s [5]. Administered at high doses, they were found to be too toxic for patients, without having a substantial antitumor effect. More recently, the azanucleosides azacitidine (5-azacytidine) and decitabine (5-aza-2'-deoxycytidine; Fig. 1) were reintroduced at lower and repeated doses: azacitidine administered subcutaneously at a dose of $75 \mathrm{mg} / \mathrm{m}^{2}$ for 7 days every 28 days, and decitabine given intravenously at a dose of 
A

\section{Cytidine}<smiles>Nc1ccn([C@@H]2O[C@H](CO)[C@@H](O)[C@H]2O)c(=O)n1</smiles>

C

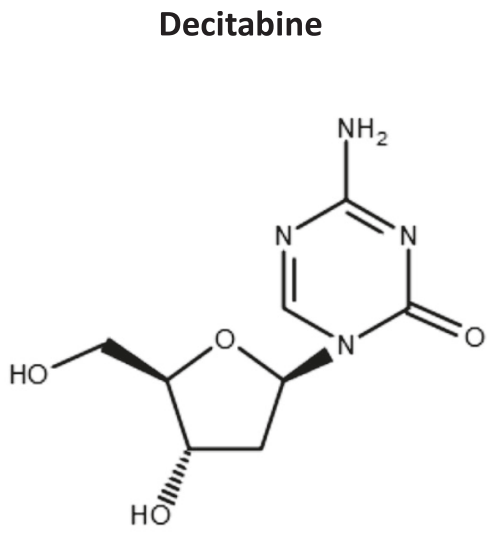

B

\section{5-azacytidine}<smiles>Nc1ncn([C@@H]2O[C@H](CO)[C@@H](O)[C@H]2O)c(=O)n1</smiles>

D

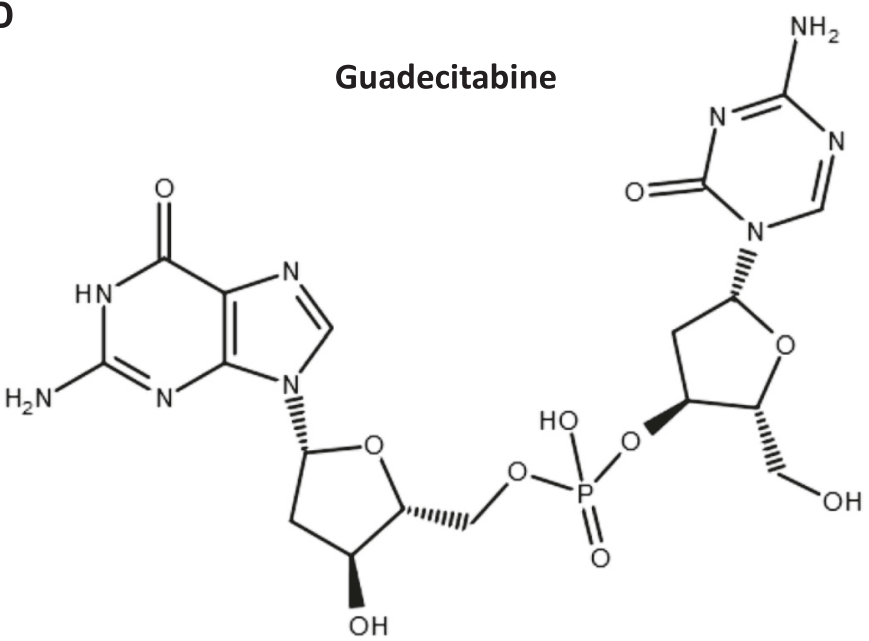

Fig. 1 Azanucleoside DNA-hypomethylating agents. Chemical structures of cytidine (A), the cytidine analogs 5-azacytidine (B) and decitabine (C), and guadecitabine (SGI-110), a dinucleotide of decitabine and deoxyguanosine (D).

$15 \mathrm{mg} / \mathrm{m}^{2}$ every $8 \mathrm{~h}$ for 3 days, repeated every 6 weeks, were shown to have beneficial effects in patients with myelodysplastic syndromes (MDS), which led to their approval by the US Food and Drug Administration (FDA) in 2004 and 2006, respectively, for the treatment of MDS [6, 7]. In addition, a 5 -day dosing regimen of decitabine given at $20 \mathrm{mg} / \mathrm{m}^{2}$ for 5 days every 28 days, allowing for easier administration in the outpatient setting, was FDA approved in 2010 and has become the clinical standard [8]. Currently, azacitidine and decitabine are broadly used not only for the treatment of MDS but also of older, medically non-fit acute myeloid leukemia (AML) patients $[9,10]$.

\section{HMA uptake, metabolism, and mechanism of action}

Azacitidine and decitabine are analogs of the nucleoside cytidine (Fig. 1). The molecular mechanism of action of
HMA has been described in detail in a recent review [11]. In brief, it comprises the cellular uptake, intracellular activation, incorporation into nucleic acids, and inhibition of DNMT thereby inducing DNA hypomethylation (Fig. 2). The cellular uptake is mediated by different nucleoside transporters $[12,13]$. Three successive phosphorylation events eventually result in the active metabolites 5-azacitidine-triphosphate for azacitidine and 5-aza-2'-deoxycytidine-triphosphate (5-aza-dCTP) for decitabine. The enzymes catalyzing the first limiting phosphorylation step are uridine-cytidine kinase (UCK) for azacitidine and deoxycytidine kinase (DCK) for decitabine (Fig. 2). HMA are considered S-phase-specific drugs because they become incorporated into DNA during replication. While decitabine is exclusively incorporated into DNA, only 10-20\% of azacitidine follows the same process, since the majority of azacitidine is incorporated into RNA. Due to the activity of cytidine deaminase (CDA), which can rapidly inactivate cytidine analogs, the half-life of subcutaneous azacitidine and intravenous decitabine in 
Fig. 2 Schematic

representation of azacitidine

and decitabine uptake

and metabolism. 5-aza-U

5-aza-uridine, 5-aza-dU 5-aza-

2'-deoxyuridine, CDP cytidine

diphosphate, CMP cytidine

monophosphate, hCNT human

concentrative nucleoside

transporter, hENT human

equilibrative nucleoside

transporter, NDPK nucleoside

diphosphate kinase, NMPK

nucleoside monophosphate

kinase, RNR ribonucleotide

reductase.

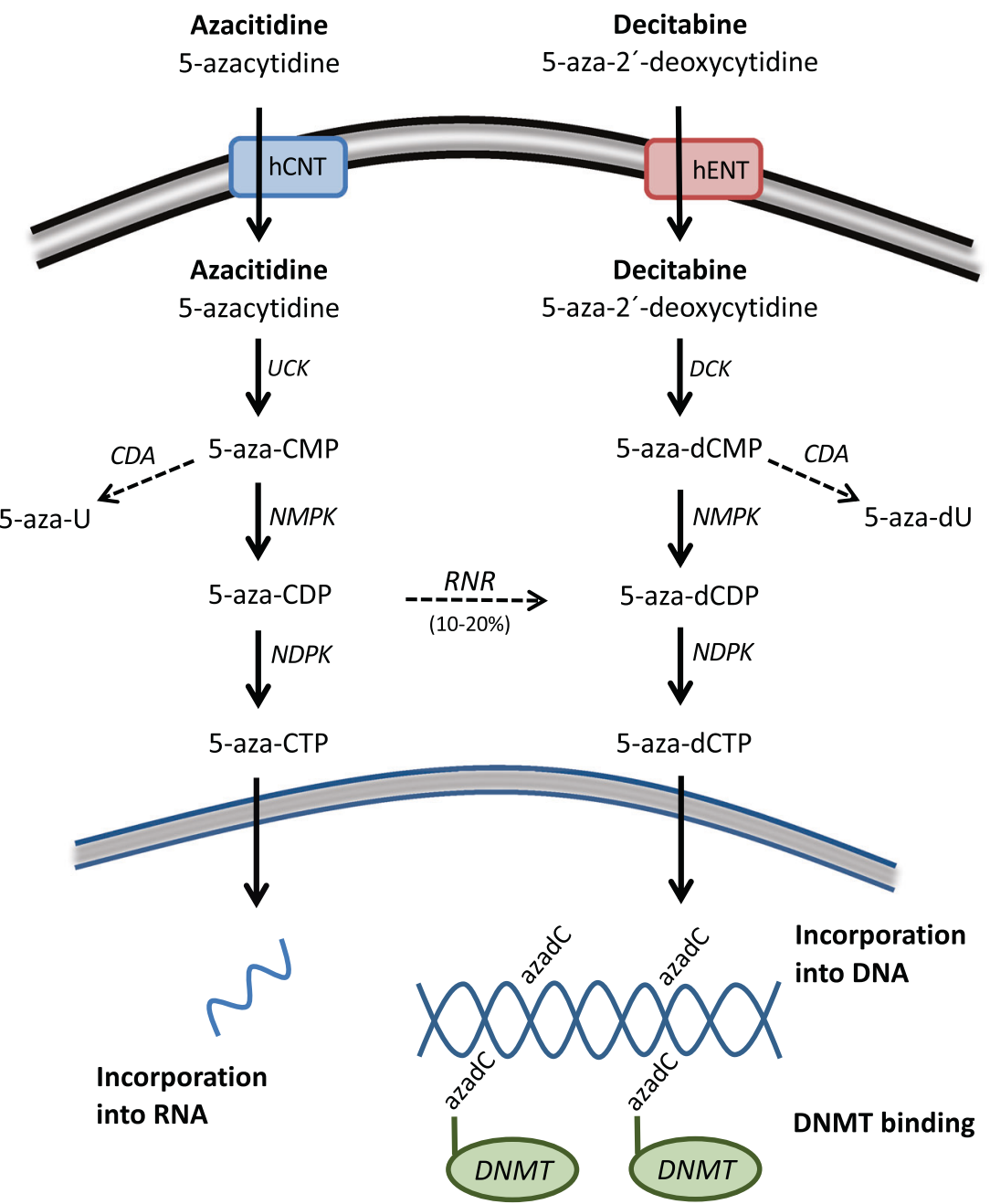

Azacitidine

Decitabine

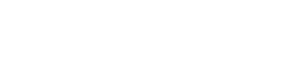


duration than those achieved in patients with wild-type TP53 (and lack of a complex-monosomal karyotype). The only curative approach, particularly in these patients, often still is provided by allogeneic hematopoietic stem cell transplantation (HSCT) alone. Hence, even in the presence of a hematologic remission, patients bearing TP53 mutations and eligible for allografting should proceed to the curative approach as soon as possible, i.e., before continued treatment leads to the development of secondary resistance. The modulating role of bi-allelic vs. single TP53 lesions as predictors of response to HMA treatment and outcome after allografting is the subject of ongoing studies. Also under study are mechanistic aspects of the (albeit transient) response to HMA in these adverse-genetics AML, whether by an interaction of mutated $\mathrm{p} 53$ protein with HMA, or by their gene-reactivating effects being particularly attracted by monosomic chromosomes (e.g., chromosome 7) presenting broad epigenetic silencing [27].

Regarding the predictive value of cytogenetic aberrations in MDS and AML patients who receive HMA therapy, a recent study including about 700 patients with higher-risk MDS or low blast count AML found that baseline cytogenetic abnormalities could not predict response to azacitidine treatment [28]. Only in the subgroup of patients with less than $20 \%$ bone marrow blasts, $3 \mathrm{q}$ abnormalities and complex karyotype were associated with a significantly lower overall response rate. No correlation between hematologic and cytogenetic response was observed in this study. Similarly, another study assessing genetic mutations and cytogenetics in 128 MDS or AML patients treated with azacitidine did not identify a clear biomarker for response or survival [29]. These results are in contrast with previous studies indicating that chromosomal aberrations, in particular abnormalities of chromosome 7 , alone or imbedded in complex-monosomal karyotypes, could be predictors of responsiveness to HMA [26, 30, 31]. Further studies are needed to determine the predictive relevance of cytogenetic information for HMA treatment.

\section{Mechanisms of resistance to HMA}

Despite initial responses to azacitidine and decitabine treatment in a subset of patients with hematologic malignancies, the development of resistance to HMA therapy is an almost inevitable problem, as shown by Prebet et al. for azacitidine already in 2011 [32]. There are two categories of resistance: primary resistance, in which patients do not show any improvement after at least 4-6 cycles of treatment, and secondary resistance, in which initially responding patients relapse after long-term treatment. The exact molecular mechanisms underlying primary or secondary HMA resistance are unknown and different factors have been proposed to be involved, including both mechanisms intrinsic to hematopoietic stem and progenitor cells, and tumor cell extrinsic factors related to immune cells and other cells in the bone marrow milieu (Fig. 3, Table 1).

\section{Tumor cell intrinsic factors}

At first, various studies focused on alterations related to HMA metabolism, which might impair HMA efficacy and contribute to both primary and secondary resistance. In vitro, resistance to decitabine was shown to be most pronounced in cancer cell lines with low mRNA expression of genes involved in decitabine uptake and activation, and high expression of CDA, the enzyme responsible for the inactivation of cytidine analogs [33]. The same study found that homozygous loss of DCK could cause resistance to decitabine in HL-60 cells. Likewise, mutations in UCK2, the equivalent to DCK in azacitidine metabolism, were shown to cause resistance to azacitidine in vitro by perturbing its activation [34]. Moreover, loss of DCK, UCK2 and the nucleoside transporter ENT1/SLC29A1 has recently been shown to play a role in resistance to azacitidine and guadecitabine in AML cell line and mouse experiments [35].

In contrast to those preclinical findings, HMA resistance in MDS patients could not be clearly linked to impaired drug metabolism thus far. As for decitabine, a subset of MDS patients with primary resistance was shown to have a higher ratio of CDA to DCK, leading to increased inactivation and decreased activation of decitabine, than patients responding to decitabine treatment [36]. The same study investigated mechanisms of secondary resistance to decitabine by comparing diagnosis and relapse samples with respect to mRNA expression levels of genes involved in decitabine metabolism, and the acquisition of DCK mutations. Neither a significant difference in gene expression nor DCK mutations could be detected at relapse. As for azacitidine, a trend towards a lower mRNA expression level of UCK1 was observed in MDS patients without a response compared to patients with a response to azacitidine treatment [37]. Using a novel mass spectrometry method to quantify the active metabolites of azacitidine in MDS and chronic myelomonocytic leukemia (CMML) patients, a recent study, however, concluded that primary resistance to azacitidine was not the result of impaired azacitidine metabolism [38]. Regarding adaptive resistance, another recent study, which analyzed DNMT1 protein levels and expression levels of key pyrimidine metabolism enzymes in serial bone marrow samples from MDS patients receiving HMA treatment, indicated that relapse might be the result of expression changes of pyrimidine metabolism enzymes preventing the depletion of DNMT1 [39]. Finally, 
Fig. 3 Cell intrinsic factors associated with resistance to HMA therapy in myeloid malignancies. $\mathrm{CYC}$ cytochrome c (release), ITGA5 integrin subunit alpha 5 .

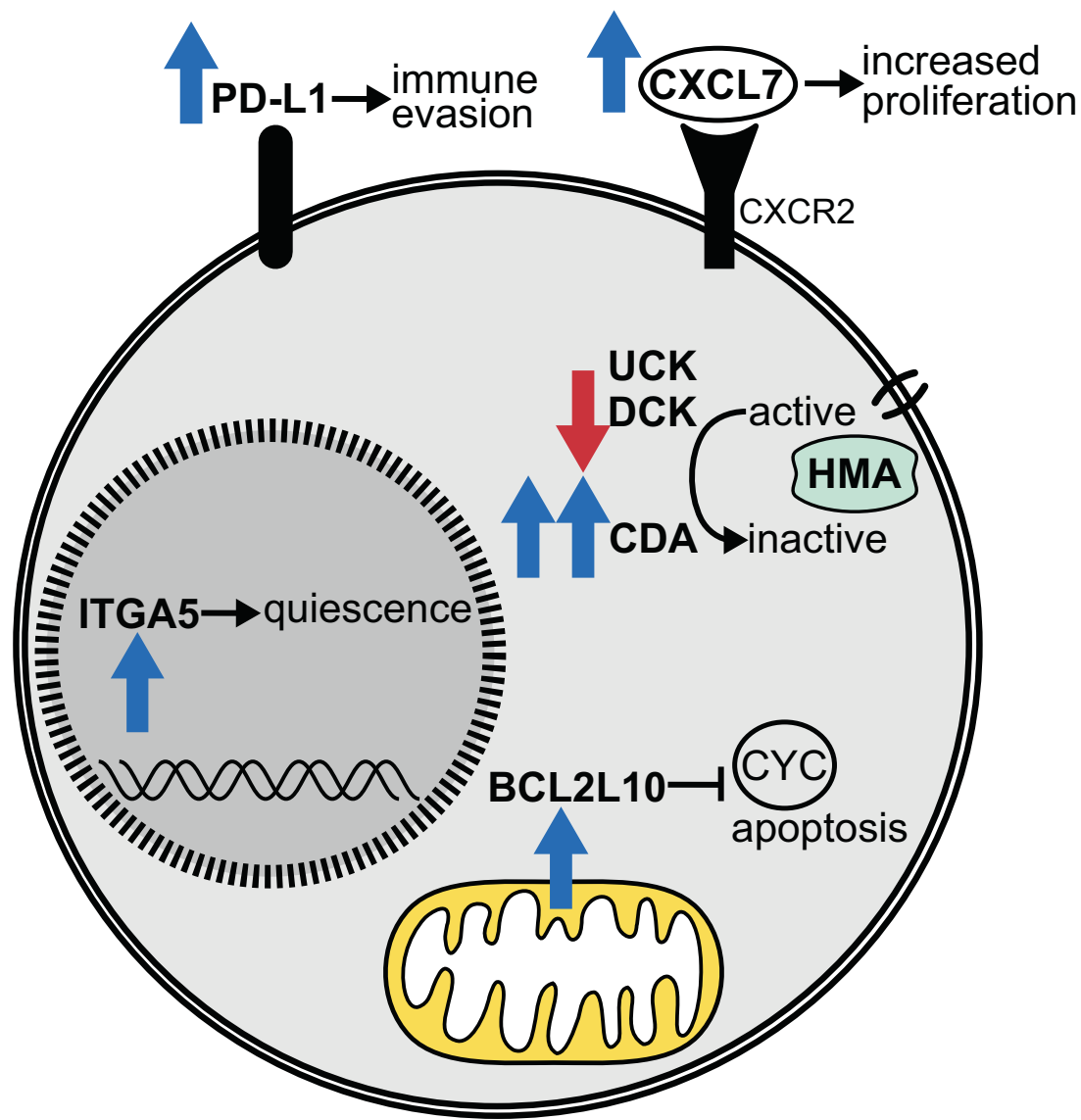

pretreatment protein levels of the triphosphohydrolase SAMHD1 in leukemic blasts were recently shown to correlate with response to decitabine but not to azacitidine in AML patients [40]. The selective inactivation of HMA demonstrated in this study was due to the fact that only the active triphosphate metabolite of decitabine but not of azacitidine functions as activator and substrate of SAMHD1.

Due to these conflicting results regarding changes in azanucleoside metabolism as potential causes of resistance, other molecular mechanisms are thought to be involved in HMA resistance. First of all, the cell cycle activity of hematopoietic cells before treatment appears to be critical for azanucleosides to be effective. MDS and CMML patients with primary resistance to azacitidine were found to have more quiescent hematopoietic progenitor cells than patients with response to azacitidine [41]. Cell cycle quiescence was shown to be mediated by integrin $\alpha 5$ signaling, which could potentially be therapeutically exploited by combining azacitidine with an integrin $\alpha 5$ inhibitor to overcome resistance. In CMML patients treated with decitabine, another study found genes associated with the cell cycle to be upregulated at diagnosis in responders compared to non-responders [42]. Non-responders showed overexpression of CXCL4 and
CXCL7 in the bone marrow, two chemokines, the former of which regulates the cell cycle activity of hematopoietic stem cells. Their overexpression might contribute to primary decitabine resistance since treatment with CXCL4 and CXCL7 was able to abrogate the effect of decitabine treatment in primary CMML cells [42].

Epigenetic differences between responders and nonresponders are another feature related to the mode of action of HMA that has been explored in the context of resistance. DNA methylation differences at baseline, primarily affecting nonpromoter regions, were shown to be predictive of response to decitabine treatment in CMML patients [42]. Assessment of global DNA methylation levels by long interspersed nuclear element-1 (LINE-1) analysis at the time of diagnosis and at relapse has shown that relapse in MDS patients treated with decitabine occurred despite hypomethylation [36]. Conversely, the hematological response of $15 \mathrm{MDS} / \mathrm{CMML}$ patients to azacitidine was associated with stable global DNA methylation levels, but significant demethylation of specific $\mathrm{CpG}$ of the EZH2 and NOTCH1 genes [43]. As for azacitidine, the majority of which is incorporated into RNA, another recent study has demonstrated that certain chromatin structures mediated by RNA cytosine methylation and RNA methyltransferases, including NSUN1, are significantly increased in leukemia cell 
Table 1 Mechanisms and biomarkers associated with resistance to HMA treatment in patients with myeloid malignancies.

\begin{tabular}{ll}
\hline & Reference \\
\hline HMA metabolism & \\
High CDA/DCK ratio & {$[36]$} \\
Low UCK and DCK expression & {$[37,39]$} \\
Non-depleted DNMT1 & {$[39]$} \\
High SAMHD1 expression & {$[40]$} \\
Cell cycle activity & \\
High number of quiescent hematopoietic & {$[41]$} \\
progenitor cells & \\
Increased integrin $\alpha 5$ signaling & {$[41]$} \\
High CXCL4 and CXCL7 expression & {$[42]$} \\
Genetic and epigenetic mechanisms & \\
Expansion of resistant subclones & {$[26,46]$} \\
Differentially methylated regions & {$[42]$} \\
Increase in RNA 5-methylcytosine and NSUN1-/ & {$[44]$} \\
BRD4-associated active chromatin & \\
Immune response & \\
Failure to upregulate inflammation-related and immune & {$[41,48]$} \\
response gene sets & \\
High expression of PD-1, PD-L1, PD-L2, and CTLA-4 & {$[65,66]$} \\
Others & \\
Persistence of leukemia stem and progenitor cells & {$[47]$} \\
High percentage of BCL2L10 expressing bone & {$[49,50]$} \\
marrow cells & \\
\hline
\end{tabular}

lines and AML/MDS patients resistant to azacitidine treatment [44].

At the genetic level, several studies showed that malignant clones are not eliminated by hypomethylating treatment, even in patients with complete morphological responses, and that the variant allele frequency remained overall stable [41, 43, 45, 46]. The expansion of resistant subclones, and the population of leukemia stem and progenitor cells not eradicated by epigenetic treatment are therefore potential causes of secondary resistance in patients initially achieving a remission [26, 46, 47].

In vitro studies demonstrating the stimulation of an antiproliferative immune response by induction of endogenous retroviruses in malignant cells provided first evidence that inflammation and immune response pathways are involved in the mode of action of HMA [22, 23]. A recent study including 40 patients with different hematologic disorders treated with azacitidine suggested that these pathways play a role also in vivo, as the induction of evolutionary young transposable elements and the activation of the innate immune system were observed in responders [48]. Similarly, another study found that inflammation and immune response pathways were upregulated in hematopoietic progenitor cells of MDS and CMML patients sensitive to azacitidine treatment whereas an alteration of those pathways was not observed in nonresponders [41].

Lastly, BCL2L10, an anti-apoptotic member of the Bcell lymphoma-2 (BCL-2) family, has been proposed as a biomarker for response to azacitidine and overall survival (OS) in AML/MDS patients. Results of a retrospective study showing a correlation between an increased percentage of BCL2L10 expressing bone marrow cells and azacitidine resistance have been confirmed prospectively $[49,50]$.

\section{Effects of HMA on immune cells (tumor cell extrinsic factors)}

In addition to their direct effects on the malignant clone in AML/MDS, HMA also demonstrate effects on cells of the immune system and the bone marrow niche (Table 2). Indeed, the enormous potential of (re)activation of an immune-mediated antitumor response has been recognized through studies of in vitro and in vivo effects of HMA over the last decade (comprehensively reviewed by Jones and colleagues [51]).

In a very recent study, systematic, serial in vivo profiling by flow cytometry was performed on different T-cell subpopulations of AML patients before and after decitabine treatment, showing an increase of CD38 expression on $\mathrm{CD}^{+}$and $\mathrm{CD}^{+} \mathrm{T}$ cells upon decitabine treatment [52]. Interestingly, $\mathrm{CD} 38$ expression on $\mathrm{CD}^{+} \mathrm{T}$ cells was negatively correlated with interferon-gamma production by $\mathrm{CD}^{+} \mathrm{T}$ cells in this study, indicating decreased $\mathrm{T}$-cell function in this model. As regards $\mathrm{CD} 8^{+} \mathrm{T}$-cell rejuvenation by exposure to an HMA, Ghoneim et al. have recently demonstrated that reversion of exhaustion-associated de novo methylation programs in $\mathrm{CD} 8^{+} \mathrm{T}$ cells was observed after sequential decitabine and anti-programmed death ligand 1 (PD-L1) treatment [53].

The induction of regulatory $\mathrm{T}$ cells by pharmacological demethylation of the FOXP3 promoter using HMA, first described by Sánchez-Abarca et al. [54] and Goodyear et al. [55], is by now well-established. Furthermore, various groups have investigated the effects of HMA on the number and function of natural killer (NK) cells, with the majority of studies demonstrating an activating effect $[56,57]$. One study reported differential effects of the two HMA, with decitabine augmenting NK cell responsiveness towards stimulation, and, in contrast, azacitidine impairing NK cell reactivity [58]. Moreover, decitabine has been shown to increase the susceptibility of AML blasts to anti-CD33 antibody and NK-mediated antibody-dependent cellular cytotoxicity [59].

Regarding dendritic cells, a clinically very relevant recent study, utilizing a murine graft-versus-leukemia model, demonstrated that decitabine is able to prime 
Table 2 Effects of HMA therapy on different immune cells in the murine system $(\mathrm{M})$ and in humans $(\mathrm{H})$.

\begin{tabular}{|c|c|c|}
\hline Cell type & HMA effect & Reference \\
\hline \multirow[t]{5}{*}{$\mathrm{T}$ cells } & Induction of $\mathrm{CD}^{+}{ }^{+} \mathrm{T}$-cell responses to tumor antigens $(\mathrm{H})$ & Goodyear et al. [55] \\
\hline & Increase in IFN-gamma ${ }^{+} \mathrm{T}$ cells $(\mathrm{H})$ & Li et al. [122] \\
\hline & Enhanced $\mathrm{CD}^{+}{ }^{+}$-cell response by upregulation of $\mathrm{MHC}-1(\mathrm{M}, \mathrm{H})$ & Luo et al. [123] \\
\hline & Improvement of T-cell frequency and repertoire in MDS $(\mathrm{H})$ & Fozza et al. [124] \\
\hline & $\begin{array}{l}\text { Reversion of exhaustion-associated de novo methylation programs } \rightarrow \text { rejuvenation } \\
\text { of exhausted } \mathrm{CD}^{+} \mathrm{T} \text { cells after sequential DAC and anti-PD-L1 treatment }(\mathrm{M})\end{array}$ & Ghoneim et al. [53] \\
\hline \multirow[t]{5}{*}{ Regulatory T cells (Tregs) } & $\begin{array}{l}\text { Expansion of Tregs after allo HSCT }(\mathrm{M}, \mathrm{H}) \text { and in autoimmune disease } \\
\text { (rodent model) }\end{array}$ & $\begin{array}{l}\text { Sánchez-Abarca et al. } \\
\text { [54] }\end{array}$ \\
\hline & & Goodyear et al. [55] \\
\hline & & Cooper et al. [125] \\
\hline & Reduction in number and function of Tregs in MDS ( $\mathrm{H}$, in vitro HMA treatment) & Fagone et al. [126] \\
\hline & & Costantini et al. [127] \\
\hline \multirow[t]{6}{*}{ Natural killer cells } & Induction of KIR expression ( $\mathrm{H}$, cell lines) & Santourlidis et al. [128] \\
\hline & & Sohlberg et al. [57] \\
\hline & Decrease or increase in NK cell functionality and number $(\mathrm{H}, \mathrm{M}$, cell lines) & Gao et al. [129] \\
\hline & & Schmiedel et al. [58] \\
\hline & & Kübler et al. [56] \\
\hline & $\begin{array}{l}\text { Increased susceptibility of AML blasts to anti-CD33 antibody and NK-mediated } \\
\text { ADCC }(\mathrm{H})\end{array}$ & Vasu et al. [59] \\
\hline \multirow[t]{3}{*}{ Dendritic cells } & Increased CD40 and CD86 expression $(\mathrm{H})$ & Frikeche et al. [130] \\
\hline & Decreased IL-10 and IL-27 secretion (H) & Kwon et al. [60] \\
\hline & Activation and increase in IFN-gamma levels (M) & \\
\hline \multirow{4}{*}{$\begin{array}{l}\text { Myeloid-derived } \\
\text { suppressor cells }\end{array}$} & Decrease in cell number $(\mathrm{M})$ & Triozzi et al. [61] \\
\hline & & Kim et al. [62] \\
\hline & & Luker et al. [63] \\
\hline & & Zhou et al. [131] \\
\hline \multirow[t]{3}{*}{$\begin{array}{l}\text { Mesenchymal stromal } \\
\text { cells (MSCs) }\end{array}$} & $\begin{array}{l}\text { Increased support of healthy over clonal (MDS) hematopoietic stem and progenitor } \\
\text { cell expansion }(\mathrm{H} \text {; coculture conditions) }\end{array}$ & Wenk et al. [64] \\
\hline & $\begin{array}{l}\text { Decrease in IL- } 6 \text { production in MSCs from MDS patients to levels found in normal } \\
\text { controls }(H \text {, in vitro AZA treatment) }\end{array}$ & Boada et al. [132] \\
\hline & Increased immunomodulation and migration ( $\mathrm{M}$, human cells) & Lee et al. [133] \\
\hline
\end{tabular}

$A D C C$ antibody-dependent cellular cytotoxicity, $A Z A$ azacitidine, $C$ cell lines, $H$ in humans, $K I R$ killer cell immunoglobulin-like receptors, $M$ in the murine system.

allogeneic immune reactions of donor lymphocyte infusions (DLI) by activating dendritic cells, also via HMA-induced increase in interferon-gamma levels [60].

In contrast, myeloid-derived suppressor cells have been shown to be reduced upon HMA treatment in tumor-bearing mice [61-63]. The function of cells of the bone marrow microenvironment, such as mesenchymal stromal cells (MSC) can also be affected by HMA treatment, as e.g., shown for MSC from MDS patients [64].

In aggregate, these various experimental approaches demonstrate that HMA are able to trigger or boost non-self recognition and cytotoxic $\mathrm{T}$-cell activity against malignant cells, and reactivate interferon-response genes, also by reactivating endogenous retroviruses resulting in "viral mimicry" via enhanced interferon-gamma response (see also [22, 23]).
With the advent of therapeutic antibodies reactivating immune checkpoints, HMA treatment has also been shown to upregulate the expression of the inhibitory immune checkpoint receptors programmed death 1 (PD-1) and cytotoxic T lymphocyte-associated antigen 4 (CTLA-4) in T cells, and their ligands PD-L1 and PD-L2 in tumor cells, respectively. MDS, CMML, and AML patients resistant to epigenetic therapy have been reported to show a trend towards a higher relative increase in PD-1, PD-L1, PD-L2, and CTLA-4 gene expression than patients who achieved a response [65]. Increased PD-1 expression upon HMA treatment has been shown to be related to PD-1 promoter demethylation in both leukemia cell lines and patient T-cell samples [65, 66], and demethylation of the PD-1 promoter to be associated with a lower response rate to azacitidine in AML/MDS [66]. Thus, upregulation of the expression of 
inhibitory immune checkpoint receptors and their ligands might result in secondary resistance to HMA treatment.

\section{Strategies to overcome HMA resistance}

HMA are broadly used in the treatment of AML and MDS. However, despite their generally accepted (albeit temporary) efficacy, the major limitation of this treatment lies in primary or secondary resistance. The rate of relapse after azacitidine treatment observed from clinical trials in MDS patients has been reported to be $36 \%$ [32]. The problem of secondary resistance raises the question of switching one HMA to another to regain drug sensitivity. While early anecdotal clinical evidence pointed to the strategy of switching from decitabine to azacitidine or vice versa in case of secondary resistance [67], subsequent retrospective studies demonstrated little benefit of such an approach, and it has not been adopted in clinical practice $[68,69]$. However, no randomized trial has compared this approach. Encouraging recent results from $\mathrm{Gu}$ et al. indicate that alternating treatment may overcome adaptive responses of the pyrimidine metabolism network, and in a mouse model has resulted in significant survival extension when both HMA were combined with the CDA inhibitor tetrahydrouridine [39]. Recent studies and clinical trials have explored novel HMA, modified treatment schedules, and combination treatments with an HMA backbone as potential strategies to overcome HMA resistance (Table 3).

\section{Novel HMA including oral formulations}

Guadecitabine (SGI-110), a dinucleotide of decitabine and deoxyguanosine (Fig. 1), is a next-generation subcutaneous HMA, which is resistant to CDA, the main enzyme responsible for decitabine degradation. The half-life of the active metabolite decitabine is longer after subcutaneous administration of guadecitabine than after intravenous administration of decitabine [70]. The extended exposure to decitabine might result in increased drug effectiveness as the incorporation of decitabine into DNA is cell cycle dependent. Guadecitabine activity has been demonstrated in phase $1 / 2$ studies in both treatment-naive and relapsed or refractory AML and MDS patients [70-72]. While the results of a phase 3 trial of guadecitabine vs. treatment choice in MDS and CMML patients previously treated with azacitidine and/or decitabine are not yet available (NCT02907359), the large randomized phase 3 trial ASTRAL-1 showed that guadecitabine was not superior to treatment choice with regard to complete remission rate and OS in treatment-naive AML patients unfit for intensive chemotherapy [73]. An additional analysis of this trial reported a survival benefit from guadecitabine as compared to treatment choice in the subgroup of patients who received at least four or six cycles [74]. In patients who received at least four cycles, median OS was 15.6 months for the guadecitabine and 13 months for the treatment choice group (hazard ratio, 0.78; 95\% confidence interval, 0.64-0.96); in patients who received at least six cycles, median OS was 19.5 and 15 months (hazard ratio, 0.69; 95\% confidence interval, 0.54-0.88), respectively.

The novel oral HMA ASTX727 consists of a fixed-dose combination of decitabine at $35 \mathrm{mg}$ and the CDA inhibitor cedazuridine at $100 \mathrm{mg}$. Cedazuridine is able to increase the oral bioavailability of decitabine by limiting its rapid CDAmediated degradation in the gut and liver. In fact, by adding cedazuridine to oral decitabine, systemic decitabine exposure has been shown in phase 1-3 studies to be equivalent to that after intravenous administration of decitabine [7577]. Randomized phase 2 and 3 trials additionally demonstrated similar DNA demethylation measured by LINE-1 assays and clinical efficacy between cedazuridine/decitabine and intravenous decitabine in MDS and CMML patients $[76,77]$. Given the equivalent systemic decitabine exposure, those results were not unexpected. In July 2020, the FDA approved the oral combination of decitabine and cedazuridine for the treatment of MDS and CMML.

Apart from its successful combination with decitabine, the novel CDA inhibitor cedazuridine has also been studied in combination with CC-486, an oral formulation of azacitidine. In animal models, the combination of oral azacitidine and cedazuridine was shown to have similar bioavailability as parenteral azacitidine [78]. Moreover, oral azacitidine and cedazuridine as well as an oral triple therapy comprising this combination plus venetoclax resulted in decreased leukemic expansion in an AML patient-derived xenograft model [78].

Single treatment with the oral azacitidine formulation CC-486 has been investigated in different clinical settings. Taking advantage of the ease of administration and the potential benefit of extended lower drug exposure with oral azacitidine, CC-486 has been proposed as postintensive chemotherapy or posttransplant maintenance therapy in AML and MDS [79, 80]. In the phase 3, randomized, placebo-controlled QUAZAR AML-001 trial, CC-486 at a dose of $300 \mathrm{mg}$ once daily on days 1-14 of 28-day cycles significantly improved OS and relapse-free survival in older AML patients who were in first remission after intensive chemotherapy and not candidates for allogeneic HSCT [79]. In the posttransplant setting, encouraging results were obtained with a 14-day dosing schedule of CC-486 maintenance therapy in a phase 1/2 dose-finding study in AML/ MDS patients in remission after HSCT [80], and this concept is being further evaluated in an ongoing phase 3 trial (NCT04173533). Lastly, CC-486 might be a treatment option for lower-risk MDS patients with transfusion- 


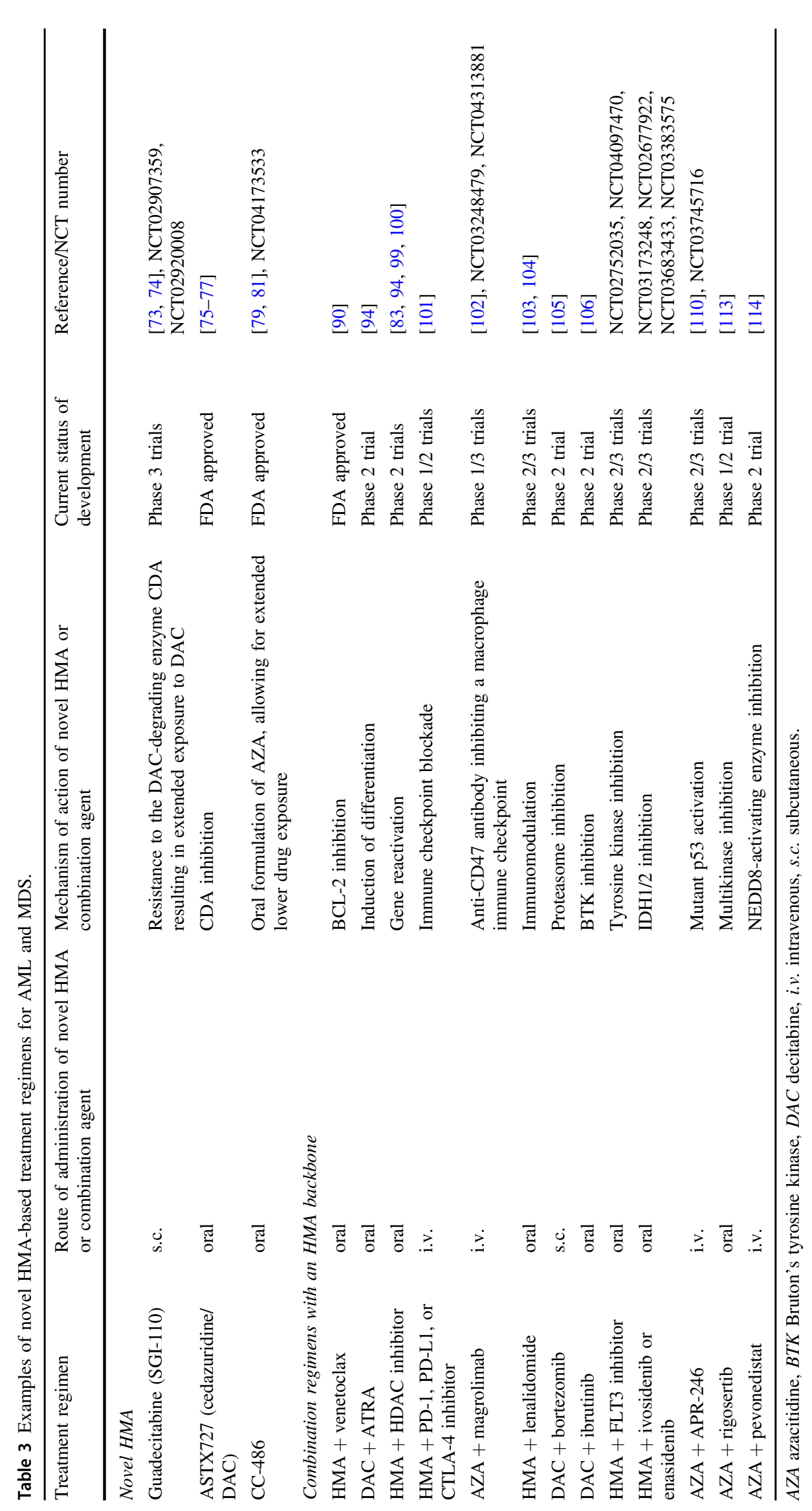


dependent anemia and thrombocytopenia as shown in a recent randomized, placebo-controlled phase 3 trial [81].

\section{Modified HMA dosing to enhance antileukemic activity}

Given the mechanism of action of HMA, with the induction of hypomethylation after S-phase dependent incorporation into DNA, alternative dosing schedules have been proposed as a way to enhance the antileukemic activity of HMA. An intensified dosing regimen of parenteral azacitidine at 75 $\mathrm{mg} / \mathrm{m}^{2}$ given for 5 days every 14 days for four cycles, which increased the number of days of azacitidine treatment during the first 8 weeks of treatment by $18 \%$, showed promising results in terms of early response rate, OS, and hematologic toxicity in a study of 26 higher-risk MDS patients [82]. A phase 2 study found that prolonged administration of subcutaneous azacitidine at a lower daily dose $\left(50 \mathrm{mg} / \mathrm{m}^{2}\right.$ given for 10 days every 28 days) increased the rate of hematologic normalization in MDS and AML patients compared to standard dosing in the reference Cancer and Leukemia Group B 9221 trial [83]. A 14- or 28day schedule of the oral azacitidine formulation CC-486 has been shown to induce sustained DNA hypomethylation over 28-day treatment cycles [84]. In the phase 3, placebocontrolled QUAZAR lower-risk MDS trial, the extended dosing regimen of CC-486 at $300 \mathrm{mg}$ for 21 days of 28-day cycles significantly reduced transfusion requirements but was associated with an increased incidence of adverse events and early deaths, indicating that the extended schedule might not be broadly applicable [81]. As mentioned above, the shorter 14-day dosing schedule of CC-486 has been proposed as maintenance therapy after intensive chemotherapy or allogeneic HSCT.

Several studies with an intensified schedule of decitabine $\left(20 \mathrm{mg} / \mathrm{m}^{2}\right.$ given on days $1-10$ of 28 -day cycles instead of on days 1-5) have shown an improved response rate in AML/MDS patients [26, 85, 86]. Based on these studies, the clinical activity of the next-generation HMA guadecitabine is under evaluation with 5- and 10-day dosing regimens. No difference in efficacy between those dosing schedules was observed in elderly, medically nonfit treatment-naive AML patients [71]. The 5-day regimen was administered in a global randomized phase 3 trial comparing guadecitabine against treatment choice in 815 treatment-naive AML patients (ASTRAL-1). As described above, this largest trial ever conducted in elderly non-fit AML patients demonstrated that guadecitabine is an active drug, and, while showing an overall similar efficacy and safety profile as standard therapy, appears to develop superiority when administered for at least 4-6 treatment cycles $[73,74]$.

\section{Combination treatments with an HMA backbone}

Combination therapies with an HMA backbone are increasingly being studied as novel agents become available for the treatment of AML/MDS, and some of them have been shown to have an effect on treatment resistance (Table 3). The combination of HMA with the BCL-2 inhibitor venetoclax is a most promising treatment approach, which has been adopted at many centers and may result in a higher depth of response and treatment prolongation by delaying resistance. Whereas HMA monotherapy fails to eradicate leukemia stem cells [47], BCL-2 inhibition has been shown to selectively eradicate leukemia stem cells by suppressing oxidative phosphorylation [87], explaining the favorable clinical activity of the combination treatment of azacitidine and venetoclax in older AML patients [88]. Moreover, transcriptional induction of the proapoptotic BH3-only protein NOXA by azacitidine has been reported as a novel mechanism of the combinatorial activity of azacitidine and venetoclax [89]. The randomized, placebo-controlled, phase 3 trial VIALE-A evaluated the combination of azacitidine plus venetoclax in newly diagnosed older AML patients ineligible for intensive therapy. In this study, improved median OS (14.7 months vs. 9.6 months; hazard ratio for death, 0.66 ; $95 \%$ confidence interval, 0.52-0.85), more rapid and more durable responses, as well as an increased incidence of transfusion independence were observed with the combination treatment [90]. Responses to the combination therapy were observed across different risk and molecular subgroups including patients with secondary AML or TP53 mutation.

Despite these promising results, resistance to venetoclax combination therapy constitutes an emerging problem in clinical practice and a few potential mechanisms of resistance have been revealed. A recently published study compared the molecular patterns of patients with response or resistance to venetoclax-based therapy in AML patients [91]. Primary or adaptive resistance to venetoclax plus HMA or low-dose cytarabine were associated primarily with FLT3-ITD, other kinase activating mutations, and TP53 alterations. Another study found that monocytic AML was more resistant to azacitidine plus venetoclax treatment than earlier developmental stages due to a loss of BCL-2 expression [92]. Pharmacologic inhibition of mitochondrial translation leading to the activation of a cellular stress response was recently demonstrated as a potential mechanism to overcome venetoclax resistance in AML [93]. Resistant AML cells were shown to be particularly sensitive to the triple combination of a ribosome-targeting antibiotic like tedizolid, venetoclax, and azacitidine, which might be a treatment regimen worth testing in future clinical trials. 
Very recently, decitabine in combination with all-trans retinoic acid (ATRA) was shown to result in a statistically significant and clinically meaningful survival extension compared to decitabine alone in elderly non-fit AML patients treated within the phase 2 DECIDER trial [94]. The results of this study suggested that the particular clinical activity of this combination may be due to the delay of resistance development. Clinical efficacy of the decitabine plus ATRA combination regimen in elderly AML patients has also been shown in two single-center studies [95, 96]. Cao et al. additionally performed in vitro studies and found a synergistic antineoplastic effect of decitabine plus ATRA on AML cells with modulation of the miR-34alpha/MYCN axis as a potential underlying mechanism [95]. Exceptional responses to the triple combination of azacitidine, ATRA, and pioglitazone were first reported in a small series of chemorefractory AML patients [97]. Moreover, this combination treatment has been shown to induce myeloid differentiation of primary AML blasts [98].

The addition of the histone deacetylase inhibitors (HDACi) entinostat, valproic acid, or vorinostat to HMA treatment has been investigated in several phase 2 clinical trials, but none of them could show an increased benefit of the combination regimen compared to HMA monotherapy in AML/MDS patients [83, 94, 99, 100]. Possible reasons why the combination of HMA and HDACi-despite the strong biological rationale of a two-pronged approach to relieve epigenetic silencing by inhibition of DNMT and HDAC - so far has not been successful in the clinic, may include additive myelotoxicity; also, simultaneous administration of both drugs may result in $\mathrm{G}_{1}$ arrest (induced by HDACi), which in turn may decrease the rate of incorporation of the HMA into DNA. For valproic acid, the serum levels achieved clinically with continued oral administration (comparable to those attained in neurological patients) may be insufficient to result in antileukemic activity.

The therapeutic role of the combination of HMA with immune checkpoint inhibitors (PD-1, PD-L1, and/or CTLA-4 inhibitors) in AML and MDS, which has been discussed in a recent review [101], is currently being evaluated in a number of ongoing phase $1 / 2$ clinical trials. Moreover, several novel anti-CD47 antibodies such as magrolimab, which inhibit a macrophage immune checkpoint, are under study in combination with azacitidine (NCT03248479, NCT04313881) [102].

Lenalidomide, approved by the FDA for the treatment of MDS, has been evaluated in combination with azacitidine in AML and MDS. Randomized studies could not demonstrate an advantage of the combination regimen over azacitidine monotherapy [103, 104]. Similarly, negative results were recently reported for the combination of 10-day decitabine and the proteasome inhibitor bortezomib in AML patients [105], and for 10-day decitabine in combination with the
Bruton's tyrosine kinase inhibitor ibrutinib in AML and MDS patients [106].

Targeted agents, such as FLT3 or IDH inhibitors, and the mutant p53 activator APR-246 constitute another group of drugs which is under investigation in combination with HMA. The combination of HMA and FLT3 inhibitor in FLT3mutated unfit AML patients has been evaluated in several phase $1 / 2$ studies, and a randomized phase 3 trial testing the combination of azacitidine with the FLT3 inhibitor gilteritinib is currently ongoing (NCT02752035). In addition, intensified treatment regimens, such as 10-day decitabine plus midostaurin (NCT04097470), or triple combinations, e.g., decitabine, venetoclax and quizartinib [107], or azacitidine, venetoclax and gilteritinib (NCT04140487) might improve treatment efficacy and are also being explored in clinical trials.

As for IDH inhibitors, different combination therapies with HMA are currently under evaluation in phase 2 and 3 trials. A randomized, placebo-controlled, phase 3 trial tests the combination of azacitidine and ivosidenib in previously untreated IDHI-mutated AML (NCT03173248). Phase 2 trials investigate the combination of azacitidine and enasidenib in newly diagnosed and recurrent or refractory IDH2mutated AML (NCT02677922, NCT03683433) [108], as well as in IDH2-mutated MDS (NCT03383575). The phase 3 IDHENTIFY trial, comparing enasidenib with conventional care regimens in patients with relapsed/refractory AML, was recently reported to have failed to meet the primary endpoint OS (NCT02577406). Analogous to the triple combination of HMA, venetoclax and FLT3 inhibitor as targeted agent for FLT3-mutated AML, the combination of azacitidine, venetoclax, and ivosidenib is under investigation for IDHI-mutated hematologic malignancies in an early-phase clinical trial (NCT03471260) [109].

Combined with azacitidine, the mutant p53 activator APR-246 has shown promising clinical activity in TP53mutated MDS and AML patients in a phase 2 study [110]. The FDA has granted breakthrough therapy designation to this combination regimen for TP53-mutated MDS patients, which is further being evaluated in a randomized phase 3 trial (NCT03745716). Moreover, the combination of APR246 and azacitidine is under investigation as maintenance therapy after allogeneic HSCT in AML and MDS patients with TP53 mutation (NCT03931291), and as part of a triple therapy with venetoclax in a phase 1 study in patients with TP53-mutated hematologic malignancies (NCT04214860).

Rigosertib, an inhibitor of the RAS-RAF-MEK and phosphatidylinositol 3-kinase pathways [111], was previously evaluated as single-agent treatment in high-risk MDS patients after HMA failure [112]. Negative results were recently reported from the phase 3 INSPIRE study on single-agent rigosertib in MDS patients after HMA treatment failure (NCT02562443). Regarding the combination of oral 
rigosertib and parenteral azacitidine, phase 1 results of a phase $1 / 2$ study in MDS and AML patients showed a safety profile similar to single-agent azacitidine and responses in 7/9 MDS/ CMML patients and 2/7 AML patients [113]. Another novel drug that is under active investigation in combination with azacitidine is the NEDD8-activating enzyme inhibitor pevonedistat. In a recent randomized phase 2 study, the combination treatment compared favorably with azacitidine monotherapy in higher-risk MDS patients [114].

Lastly, the combination of HMA with standard chemotherapy is not to be neglected in the context of resistance. The concept of epigenetic priming with decitabine prior to standard induction chemotherapy has proved to be feasible in a phase 1 study of AML patients [115]. Recently, the combination of HMA and standard chemotherapy has been demonstrated in preclinical models to prevent the development of chemoresistant AML relapses through a decrease in AML clones with stemness properties like quiescence and leukemia-initiating capacity [116], providing a rationale for further research on this combination therapy.

Finally, the addition of HMA to DLI, a combination regimen reserved for patients having undergone allogeneic HSCT, can be safe and effective in relapsed AML and MDS patients $[117,118]$. Interestingly, the combination of HMA and DLI may enhance the graft-versus-leukemia effect of the donor lymphocytes. The optimal timing as well as DLI dosing are not yet determined, and as shown by Kwon et al. [60], the specific timing of serial dosing may enhance the graft-versus-leukemia effect in a mouse model, while at the same time reducing graft-versus-host disease.

Regarding the feasibility of combinatorial approaches with an HMA backbone, the effects of additive myelotoxicity have to be taken into account, particularly in elderly, medically non-fit AML/MDS patients. Thus, the experience so far demonstrates that even with well-tolerated single-agent administration of an antibody conjugate (e.g., the anti-CD33 antibody vadastuximab talirine, SGNCD33A) [119], the combination with an HMA may lead to unacceptable myelotoxicity [120]. A similar experience exists for the Polo-like kinase 1 inhibitor volasertib, demonstrating promising results in combination with lowdose cytarabine [121], but necessitating re-evaluation of dose and safety profile when combined with HMA. On the other hand, non-myelotoxic combination partners, such as ascorbic acid or retinoic acid are less likely to result in aggravation of the hematologic toxicity profile of HMA.

\section{Conclusions and outlook}

Dysregulated DNA methylation is a key event in tumor initiation and progression. Targeting DNA methylation using HMA has been a major advance in the treatment of several myeloid neoplasms. The first generation of HMA, i.e., azacitidine and decitabine, has become a cornerstone of MDS and AML treatment. The improved understanding of the mode of action of these agents, together with increasing knowledge about mechanisms of resistance, can inform the selection of patients for HMA therapy, as well as the development of novel HMA and combination treatments with an HMA backbone. Triple combinations including also BCL-2 inhibition or other targeted agents, as well as HMA maintenance therapy are research areas under active investigation. As more and more therapeutic options become available for the treatment of MDS and AML, the sequential use of therapies might be an alternative to combination regimens, and also help to overcome treatment resistance. In order to improve HMA efficacy, studies of new treatment approaches include research on predictive biomarkers.

Acknowledgements We thank Maya André for helpful discussions, and Manfred Jung for help with creating the figures. JS is a Fellow of the SUCCESS program of the Department of Hematology, Oncology and Stem Cell Transplantation of the University of Freiburg Medical Center. ML receives funding by the Deutsche Forschungsgemeinschaft (CRC 992 Medical Epigenetics, Project ID 192904750; FOR 2674, Project ID A05, A09) and DKTK (Project ID L637, L660).

Funding Open Access funding enabled and organized by Projekt DEAL.

\section{Compliance with ethical standards}

Conflict of interest ML has received research funding and travel support from Janssen-Cilag, study drugs from TEVA, Cheplapharm and Aristopharm, and compensation as a member of the scientific advisory board of Janssen-Cilag and Astex. All the other authors declare no potential competing interests.

Publisher's note Springer Nature remains neutral with regard to jurisdictional claims in published maps and institutional affiliations.

Open Access This article is licensed under a Creative Commons Attribution 4.0 International License, which permits use, sharing, adaptation, distribution and reproduction in any medium or format, as long as you give appropriate credit to the original author(s) and the source, provide a link to the Creative Commons license, and indicate if changes were made. The images or other third party material in this article are included in the article's Creative Commons license, unless indicated otherwise in a credit line to the material. If material is not included in the article's Creative Commons license and your intended use is not permitted by statutory regulation or exceeds the permitted use, you will need to obtain permission directly from the copyright holder. To view a copy of this license, visit http://creativecommons. org/licenses/by/4.0/.

\section{References}

1. Baylin SB, Jones PA. A decade of exploring the cancer epigenome - biological and translational implications. Nat Rev Cancer. 2011;11:726-34. 
2. Robertson KD. DNA methylation and human disease. Nat Rev Genet. 2005;6:597-610.

3. Gruenbaum Y, Cedar H, Razin A. Substrate and sequence specificity of a eukaryotic DNA methylase. Nature. 1982;295:620-2.

4. Okano M, Bell DW, Haber DA, Li E. DNA methyltransferases Dnmt3a and Dnmt3b are essential for de novo methylation and mammalian development. Cell. 1999;99:247-57.

5. Sorm F, Piskala A, Cihak A, Vesely J. 5-Azacytidine, a new, highly effective cancerostatic. Experientia. 1964;20:202-3.

6. Kantarjian H, Issa JP, Rosenfeld CS, Bennett JM, Albitar M, DiPersio $J$, et al. Decitabine improves patient outcomes in myelodysplastic syndromes: results of a phase III randomized study. Cancer. 2006;106:1794-803.

7. Lübbert M, Suciu S, Baila L, Ruter BH, Platzbecker U, Giagounidis A, et al. Low-dose decitabine versus best supportive care in elderly patients with intermediate- or high-risk myelodysplastic syndrome (MDS) ineligible for intensive chemotherapy: final results of the randomized phase III study of the European Organisation for Research and Treatment of Cancer Leukemia Group and the German MDS Study Group. J Clin Oncol. 2011;29:1987-96.

8. Steensma DP, Baer MR, Slack JL, Buckstein R, Godley LA, Garcia-Manero G, et al. Multicenter study of decitabine administered daily for 5 days every 4 weeks to adults with myelodysplastic syndromes: the alternative dosing for outpatient treatment (ADOPT) trial. J Clin Oncol. 2009;27:3842-8.

9. Dombret H, Seymour JF, Butrym A, Wierzbowska A, Selleslag $\mathrm{D}$, Jang $\mathrm{JH}$, et al. International phase 3 study of azacitidine vs conventional care regimens in older patients with newly diagnosed AML with $>30 \%$ blasts. Blood. 2015;126:291-9.

10. Kantarjian HM, Thomas XG, Dmoszynska A, Wierzbowska A, Mazur G, Mayer J, et al. Multicenter, randomized, open-label, phase III trial of decitabine versus patient choice, with physician advice, of either supportive care or low-dose cytarabine for the treatment of older patients with newly diagnosed acute myeloid leukemia. J Clin Oncol. 2012;30:2670-7.

11. Diesch J, Zwick A, Garz AK, Palau A, Buschbeck M, Götze KS. A clinical-molecular update on azanucleoside-based therapy for the treatment of hematologic cancers. Clin Epigenetics. 2016;8:71.

12. Rius M, Stresemann C, Keller D, Brom M, Schirrmacher E, Keppler D, et al. Human concentrative nucleoside transporter 1mediated uptake of 5-azacytidine enhances DNA demethylation. Mol Cancer Ther. 2009;8:225-31.

13. Ueda K, Hosokawa M, Iwakawa S. Cellular uptake of decitabine by equilibrative nucleoside transporters in HCT116 cells. Biol Pharm Bull. 2015;38:1113-9.

14. Marcucci G, Silverman L, Eller M, Lintz L, Beach CL. Bioavailability of azacitidine subcutaneous versus intravenous in patients with the myelodysplastic syndromes. J Clin Pharm. 2005;45:597-602.

15. Cashen AF, Shah AK, Todt L, Fisher N, DiPersio J. Pharmacokinetics of decitabine administered as a 3-h infusion to patients with acute myeloid leukemia (AML) or myelodysplastic syndrome (MDS). Cancer Chemother Pharm. 2008;61:759-66.

16. Mahfouz RZ, Jankowska A, Ebrahem Q, Gu X, Visconte V, Tabarroki A, et al. Increased CDA expression/activity in males contributes to decreased cytidine analog half-life and likely contributes to worse outcomes with 5-azacytidine or decitabine therapy. Clin Cancer Res. 2013;19:938-48.

17. Rogstad DK, Herring JL, Theruvathu JA, Burdzy A, Perry CC, Neidigh JW, et al. Chemical decomposition of 5-aza-2'deoxycytidine (Decitabine): kinetic analyses and identification of products by NMR, HPLC, and mass spectrometry. Chem Res Toxicol. 2009;22:1194-204.

18. Leonhardt H, Page AW, Weier HU, Bestor TH. A targeting sequence directs DNA methyltransferase to sites of DNA replication in mammalian nuclei. Cell. 1992;71:865-73.
19. Ghoshal K, Datta J, Majumder S, Bai S, Kutay H, Motiwala T, et al. 5-Aza-deoxycytidine induces selective degradation of DNA methyltransferase 1 by a proteasomal pathway that requires the KEN box, bromo-adjacent homology domain, and nuclear localization signal. Mol Cell Biol. 2005;25:4727-41.

20. Patel K, Dickson J, Din S, Macleod K, Jodrell D, Ramsahoye B. Targeting of 5-aza-2'-deoxycytidine residues by chromatinassociated DNMT1 induces proteasomal degradation of the free enzyme. Nucleic Acids Res. 2010;38:4313-24.

21. Issa JP, Kantarjian HM. Targeting DNA methylation. Clin Cancer Res. 2009;15:3938-46.

22. Roulois D, Loo Yau H, Singhania R, Wang Y, Danesh A, Shen SY, et al. DNA-demethylating agents target colorectal cancer cells by inducing viral mimicry by endogenous transcripts. Cell. 2015;162:961-73.

23. Chiappinelli KB, Strissel PL, Desrichard A, Li H, Henke C, Akman B, et al. Inhibiting DNA methylation causes an interferon response in cancer via dsRNA including endogenous retroviruses. Cell. 2015;162:974-86.

24. Stomper J, Lübbert M. Can we predict responsiveness to hypomethylating agents in AML? Semin Hematol. 2019;56: 118-24.

25. Nazha A, Sekeres MA, Bejar R, Rauh MJ, Othus M, Komrokji RS, et al. Genomic biomarkers to predict resistance to hypomethylating agents in patients with myelodysplastic syndromes using artificial intelligence. JCO Precis Oncol. 2019;3:PO.19.00119.

26. Welch JS, Petti AA, Miller CA, Fronick CC, O'Laughlin M, Fulton RS, et al. TP53 and decitabine in acute myeloid leukemia and myelodysplastic syndromes. N. Engl J Med. 2016;375:2023-36.

27. Greve G, Schüler J, Grüning BA, Berberich B, Stomper J, Zimmer $\mathrm{D}$, et al. Decitabine induces gene derepression on monosomic chromosomes: in vitro and in vivo effects in adverserisk cytogenetics AML. Cancer Res. 2020. https://doi.org/10. 1158/0008-5472.

28. Sebert M, Komrokji RS, Sekeres MA, Prebet T, Cluzeau T, Santini V, et al. Impact of baseline cytogenetic findings and cytogenetic response on outcome of high-risk myelodysplastic syndromes and low blast count AML treated with azacitidine. Leuk Res. 2017;63:72-7.

29. Kuendgen A, Müller-Thomas C, Lauseker M, Haferlach T, Urbaniak P, Schroeder T, et al. Efficacy of azacitidine is independent of molecular and clinical characteristics - an analysis of 128 patients with myelodysplastic syndromes or acute myeloid leukemia and a review of the literature. Oncotarget. 2018;9:27882-94.

30. Lübbert M, Wijermans P, Kunzmann R, Verhoef G, Bosly A, Ravoet $\mathrm{C}$, et al. Cytogenetic responses in high-risk myelodysplastic syndrome following low-dose treatment with the DNA methylation inhibitor 5-aza-2'-deoxycytidine. Br J Haematol. 2001;114:349-57.

31. Raj K, John A, Ho A, Chronis C, Khan S, Samuel J, et al. CDKN2B methylation status and isolated chromosome 7 abnormalities predict responses to treatment with 5-azacytidine. Leukemia. 2007;21:1937-44.

32. Prebet T, Gore SD, Esterni B, Gardin C, Itzykson R, Thepot S, et al. Outcome of high-risk myelodysplastic syndrome after azacitidine treatment failure. J Clin Oncol. 2011;29:3322-7.

33. Qin T, Jelinek J, Si J, Shu J, Issa JP. Mechanisms of resistance to 5-aza-2'-deoxycytidine in human cancer cell lines. Blood. 2009; 113:659-67.

34. Sripayap P, Nagai T, Uesawa M, Kobayashi $H$, Tsukahara $T$, Ohmine $\mathrm{K}$, et al. Mechanisms of resistance to azacitidine in human leukemia cell lines. Exp Hematol. 2014;42:294-306 e2.

35. Gruber E, Franich RL, Shortt J, Johnstone RW, Kats LM. Distinct and overlapping mechanisms of resistance to azacytidine and guadecitabine in acute myeloid leukemia. Leukemia. 2020; 34:3388-92. 
36. Qin T, Castoro R, El Ahdab S, Jelinek J, Wang X, Si J, et al. Mechanisms of resistance to decitabine in the myelodysplastic syndrome. PLoS One. 2011;6:e23372.

37. Valencia A, Masala E, Rossi A, Martino A, Sanna A, Buchi F, et al. Expression of nucleoside-metabolizing enzymes in myelodysplastic syndromes and modulation of response to azacitidine. Leukemia. 2014;28:621-8.

38. Unnikrishnan A, Vo ANQ, Pickford R, Raftery MJ, Nunez AC, Verma A, et al. AZA-MS: a novel multiparameter mass spectrometry method to determine the intracellular dynamics of azacitidine therapy in vivo. Leukemia. 2018;32:900-10.

39. Gu X, Tohme R, Tomlinson B, Sakre N, Hasipek M, Durkin L, et al. Decitabine- and 5-azacytidine resistance emerges from adaptive responses of the pyrimidine metabolism network. Leukemia. 2020. https://doi.org/10.1038/s41375-020-1003-x.

40. Oellerich T, Schneider C, Thomas D, Knecht KM, Buzovetsky $\mathrm{O}$, Kaderali L, et al. Selective inactivation of hypomethylating agents by SAMHD1 provides a rationale for therapeutic stratification in AML. Nat Commun. 2019;10:3475.

41. Unnikrishnan A, Papaemmanuil E, Beck D, Deshpande NP, Verma A, Kumari A, et al. Integrative genomics identifies the molecular basis of resistance to azacitidine therapy in myelodysplastic syndromes. Cell Rep. 2017;20:572-85.

42. Meldi K, Qin T, Buchi F, Droin N, Sotzen J, Micol JB, et al. Specific molecular signatures predict decitabine response in chronic myelomonocytic leukemia. J Clin Investig. 2015;125:1857-72.

43. Gawlitza AL, Speith J, Rinke J, Sajzew R, Muller EK, Schafer $\mathrm{V}$, et al. 5-Azacytidine modulates $\mathrm{CpG}$ methylation levels of EZH2 and NOTCH1 in myelodysplastic syndromes. J Cancer Res Clin Oncol. 2019;145:2835-43.

44. Cheng JX, Chen L, Li Y, Cloe A, Yue M, Wei J, et al. RNA cytosine methylation and methyltransferases mediate chromatin organization and 5-azacytidine response and resistance in leukaemia. Nat Commun. 2018;9:1163.

45. Merlevede J, Droin N, Qin T, Meldi K, Yoshida K, Morabito M, et al. Mutation allele burden remains unchanged in chronic myelomonocytic leukaemia responding to hypomethylating agents. Nat Commun. 2016;7:10767.

46. Uy GL, Duncavage EJ, Chang GS, Jacoby MA, Miller CA, Shao J, et al. Dynamic changes in the clonal structure of MDS and AML in response to epigenetic therapy. Leukemia. 2017;31:872-81.

47. Craddock C, Quek L, Goardon N, Freeman S, Siddique S, Raghavan M, et al. Azacitidine fails to eradicate leukemic stem/ progenitor cell populations in patients with acute myeloid leukemia and myelodysplasia. Leukemia. 2013;27:1028-36.

48. Ohtani H, Orskov AD, Helbo AS, Gillberg L, Liu M, Zhou W, et al. Activation of a subset of evolutionarily young transposable elements and innate immunity are linked to clinical responses to 5-azacytidine. Cancer Res. 2020;80:2441-50.

49. Cluzeau T, Robert G, Mounier N, Karsenti JM, Dufies M, Puissant A, et al. BCL2L10 is a predictive factor for resistance to azacitidine in MDS and AML patients. Oncotarget. 2012;3:490-501.

50. Vidal V, Robert G, Goursaud L, Durand L, Ginet C, Karsenti JM, et al. BCL2L10 positive cells in bone marrow are an independent prognostic factor of azacitidine outcome in myelodysplastic syndrome and acute myeloid leukemia. Oncotarget. 2017;8:47103-9.

51. Jones PA, Ohtani H, Chakravarthy A, De Carvalho DD. Epigenetic therapy in immune-oncology. Nat Rev Cancer. 2019;19:151-61.

52. Zhao C, Jia B, Wang M, Schell TD, Claxton DF, Ehmann WC, et al. Multi-dimensional analysis identifies an immune signature predicting response to decitabine treatment in elderly patients with AML. Br J Haematol. 2020;188:674-84.

53. Ghoneim HE, Fan Y, Moustaki A, Abdelsamed HA, Dash P, Dogra P, et al. De novo epigenetic programs inhibit PD-1 blockade-mediated T cell rejuvenation. Cell. 2017;170:142-57 e19.
54. Sanchez-Abarca LI, Gutierrez-Cosio S, Santamaria C, CaballeroVelazquez T, Blanco B, Herrero-Sanchez C, et al. Immunomodulatory effect of 5-azacytidine $(5$-azaC): potential role in the transplantation setting. Blood. 2010;115:107-21.

55. Goodyear OC, Dennis M, Jilani NY, Loke J, Siddique S, Ryan $\mathrm{G}$, et al. Azacitidine augments expansion of regulatory $\mathrm{T}$ cells after allogeneic stem cell transplantation in patients with acute myeloid leukemia (AML). Blood. 2012;119:3361-9.

56. Kübler A, Woiterski J, Witte KE, Buhring HJ, Hartwig UF, Ebinger M, et al. Both mature KIR+ and immature KIR- NK cells control pediatric acute B-cell precursor leukemia in NOD. Cg-Prkdcscid IL2rgtmWjl/Sz mice. Blood. 2014;124:3914-23.

57. Sohlberg E, Pfefferle A, Andersson S, Baumann BC, HellströmLindberg E, Malmberg KJ. Imprint of 5-azacytidine on the natural killer cell repertoire during systemic treatment for high-risk myelodysplastic syndrome. Oncotarget. 2015;6:34178-90.

58. Schmiedel BJ, Arelin V, Gruenebach F, Krusch M, Schmidt SM, Salih HR. Azacytidine impairs NK cell reactivity while decitabine augments NK cell responsiveness toward stimulation. Int $\mathrm{J}$ Cancer. 2011;128:2911-22.

59. Vasu S, He S, Cheney C, Gopalakrishnan B, Mani R, Lozanski $\mathrm{G}$, et al. Decitabine enhances anti-CD33 monoclonal antibody BI 836858-mediated natural killer ADCC against AML blasts. Blood. 2016;127:2879-89.

60. Kwon YR, Kim HJ, Sohn MJ, Lim JY, Park KS, Lee S, et al. Effects of decitabine on allogeneic immune reactions of donor lymphocyte infusion via activation of dendritic cells. Exp Hematol Oncol. 2020;9:22.

61. Triozzi PL, Aldrich W, Achberger S, Ponnazhagan S, Alcazar O, Saunthararajah Y. Differential effects of low-dose decitabine on immune effector and suppressor responses in melanoma-bearing mice. Cancer Immunol Immunother. 2012;61:1441-50.

62. Kim K, Skora AD, Li Z, Liu Q, Tam AJ, Blosser RL, et al. Eradication of metastatic mouse cancers resistant to immune checkpoint blockade by suppression of myeloid-derived cells. Proc Natl Acad Sci USA. 2014;111:11774-9.

63. Luker AJ, Graham LJ, Smith TM Jr., Camarena C, Zellner MP, Gilmer JS, et al. The DNA methyltransferase inhibitor, guadecitabine, targets tumor-induced myelopoiesis and recovers $\mathrm{T}$ cell activity to slow tumor growth in combination with adoptive immunotherapy in a mouse model of breast cancer. BMC Immunol. 2020;21:8.

64. Wenk C, Garz AK, Grath S, Huberle C, Witham D, Weickert M, et al. Direct modulation of the bone marrow mesenchymal stromal cell compartment by azacitidine enhances healthy hematopoiesis. Blood Adv. 2018;2:3447-61.

65. Yang H, Bueso-Ramos C, DiNardo C, Estecio MR, Davanlou M, Geng QR, et al. Expression of PD-L1, PD-L2, PD-1 and CTLA4 in myelodysplastic syndromes is enhanced by treatment with hypomethylating agents. Leukemia. 2014;28:1280-8.

66. Orskov AD, Treppendahl MB, Skovbo A, Holm MS, Friis LS, Hokland M, et al. Hypomethylation and up-regulation of PD-1 in $\mathrm{T}$ cells by azacytidine in MDS/AML patients: a rationale for combined targeting of PD-1 and DNA methylation. Oncotarget. 2015;6:9612-26.

67. Borthakur G, Ahdab SE, Ravandi F, Faderl S, Ferrajoli A, Newman B, et al. Activity of decitabine in patients with myelodysplastic syndrome previously treated with azacitidine. Leuk Lymphoma. 2008;49:690-5.

68. Duong VH, Bhatnagar B, Zandberg DP, Vannorsdall EJ, Tidwell ML, Chen Q, et al. Lack of objective response of myelodysplastic syndromes and acute myeloid leukemia to decitabine after failure of azacitidine. Leuk Lymphoma. 2015;56:1718-22.

69. Harel S, Cherait A, Berthon C, Willekens C, Park S, Rigal M, et al. Outcome of patients with high risk Myelodysplastic Syndrome (MDS) and advanced chronic myelomonocytic leukemia 
(CMML) treated with decitabine after azacitidine failure. Leuk Res. 2015;39:501-4.

70. Issa JJ, Roboz G, Rizzieri D, Jabbour E, Stock W, O'Connell C, et al. Safety and tolerability of guadecitabine (SGI-110) in patients with myelodysplastic syndrome and acute myeloid leukaemia: a multicentre, randomised, dose-escalation phase 1 study. Lancet Oncol. 2015;16:1099-110.

71. Kantarjian HM, Roboz GJ, Kropf PL, Yee KWL, O'Connell CL, Tibes R, et al. Guadecitabine (SGI-110) in treatment-naive patients with acute myeloid leukaemia: phase 2 results from a multicentre, randomised, phase 1/2 trial. Lancet Oncol. 2017;18:1317-26.

72. Garcia-Manero G, Roboz G, Walsh K, Kantarjian H, Ritchie E, Kropf P, et al. Guadecitabine (SGI-110) in patients with intermediate or high-risk myelodysplastic syndromes: phase 2 results from a multicentre, open-label, randomised, phase 1/2 trial. Lancet Haematol. 2019;6:e317-27.

73. Fenaux P, Gobbi M, Kropf PL, Mayer J, Roboz GJ, Döhner H, et al. Results of ASTRAL-1 study, a phase 3 randomized trial of guadecitabine $(\mathrm{G})$ vs treatment choice (TC) in treatment naive acute myeloid leukemia (TN-AML) not eligible for intensive chemotherapy (IC). EHA Library. 2019;267462(S879).

74. Roboz GJ, Döhner H, Gobbi M, Kropf PL, Mayer J, Krauter J, et al. Results from a Global Randomized Phase 3 Study of Guadecitabine (G) vs treatment choice (TC) in 815 patients with treatment naïve (TN) AML unfit for intensive chemotherapy (IC) ASTRAL-1 Study: analysis by number of cycles. Blood. 2019; 134:2591.

75. Savona MR, Odenike O, Amrein PC, Steensma DP, DeZern AE, Michaelis LC, et al. An oral fixed-dose combination of decitabine and cedazuridine in myelodysplastic syndromes: a multicentre, open-label, dose-escalation, phase 1 study. Lancet Haematol. 2019; 6:e194-e203.

76. Garcia-Manero G, Griffiths EA, Steensma DP, Roboz GJ, Wells $\mathrm{R}, \mathrm{McCloskey} \mathrm{J}$, et al. Oral cedazuridine/decitabine for MDS and CMML: a phase 2 pharmacokinetic/pharmacodynamic randomized crossover study. Blood. 2020;136:674-83.

77. Garcia-Manero G, McCloskey J, Griffiths EA, Yee KWL, Zeidan AM, Al-Kali A, et al. Pharmacokinetic exposure equivalence and preliminary efficacy and safety from a randomized cross over Phase 3 Study (ASCERTAIN study) of an oral hypomethylating agent ASTX727 (cedazuridine/decitabine) compared to IV decitabine. Blood. 2019;134:846.

78. Ramsey HE, Oganesian A, Gorska AE, Fuller L, Arrate M, Boyd $\mathrm{K}$, et al. Oral azacitidine and cedazuridine approximate parenteral azacitidine efficacy in murine model. Target Oncol. 2020;15:231-40.

79. Wei AH, Dohner H, Pocock C, Montesinos P, Afanasyev B, Dombret $\mathrm{H}$, et al. Oral azacitidine maintenance therapy for acute myeloid leukemia in First Remission N. Engl J Med. 2020;383: 2526-37.

80. de Lima M, Oran B, Champlin RE, Papadopoulos EB, Giralt SA, Scott BL, et al. CC-486 maintenance after stem cell transplantation in patients with acute myeloid leukemia or myelodysplastic syndromes. Biol Blood Marrow Transpl. 2018;24:2017-24.

81. Garcia-Manero G, Santini V, Almeida A, Platzbecker U, Jonasova A, Silverman L, et al. A phase III placebo-controlled trial of CC-486 in patients with red blood cell transfusion-dependent (RBC-TD) anemia and thrombocytopenia due to IPSS lower-risk myelodysplastic syndromes. EHA Library. 2020;295000(S180).

82. Ades L, Guerci-Bresler A, Cony-Makhoul P, Legros L, Sebert M, Braun T, et al. A phase II study of the efficacy and safety of an intensified schedule of azacytidine in intermediate- 2 and high-risk patients with myelodysplastic syndromes: a study by the Groupe Francophone des Myelodysplasies (GFM). Haematologica. 2019; 104:e131-3.
83. Prebet T, Sun Z, Figueroa ME, Ketterling R, Melnick A, Greenberg PL, et al. Prolonged administration of azacitidine with or without entinostat for myelodysplastic syndrome and acute myeloid leukemia with myelodysplasia-related changes: results of the US Leukemia Intergroup trial E1905. J Clin Oncol. 2014;32:1242-8.

84. Laille E, Shi T, Garcia-Manero G, Cogle CR, Gore SD, Hetzer J, et al. Pharmacokinetics and pharmacodynamics with extended dosing of CC-486 in patients with hematologic malignancies. PLoS One. 2015;10:e0135520.

85. Blum W, Garzon R, Klisovic RB, Schwind S, Walker A, Geyer $\mathrm{S}$, et al. Clinical response and miR-29b predictive significance in older AML patients treated with a 10-day schedule of decitabine. Proc Natl Acad Sci USA. 2010;107:7473-8.

86. Ritchie EK, Feldman EJ, Christos PJ, Rohan SD, Lagassa CB, Ippoliti C, et al. Decitabine in patients with newly diagnosed and relapsed acute myeloid leukemia. Leuk Lymphoma. 2013;54: 2003-7.

87. Lagadinou ED, Sach A, Callahan K, Rossi RM, Neering SJ, Minhajuddin M, et al. BCL-2 inhibition targets oxidative phosphorylation and selectively eradicates quiescent human leukemia stem cells. Cell Stem Cell. 2013;12:329-41.

88. Pollyea DA, Stevens BM, Jones CL, Winters A, Pei S, Minhajuddin $\mathrm{M}$, et al. Venetoclax with azacitidine disrupts energy metabolism and targets leukemia stem cells in patients with acute myeloid leukemia. Nat Med. 2018;24:1859-66.

89. Jin S, Cojocari D, Purkal JJ, Popovic R, Talaty NN, Xiao Y, et al. 5-azacitidine induces NOXA to prime AML Cells for venetoclaxmediated apoptosis. Clin Cancer Res. 2020;26:3371-83.

90. DiNardo CD, Jonas BA, Pullarkat V, Thirman MJ, Garcia JS, Wei $\mathrm{AH}$, et al. Azacitidine and venetoclax in previously untreated acute myeloid leukemia. N. Engl J Med. 2020;383:617-29.

91. DiNardo CD, Tiong IS, Quaglieri A, MacRaild S, Loghavi S, Brown FC, et al. Molecular patterns of response and treatment failure after frontline venetoclax combinations in older patients with AML. Blood. 2020;135:791-803.

92. Pei S, Pollyea DA, Gustafson A, Stevens BM, Minhajuddin M, Fu R, et al. Monocytic subclones confer resistance to venetoclaxbased therapy in patients with acute myeloid leukemia. Cancer Discov. 2020;10:536-51.

93. Sharon D, Cathelin S, Mirali S, Di Trani JM, Yanofsky DJ, Keon $\mathrm{KA}$, et al. Inhibition of mitochondrial translation overcomes venetoclax resistance in AML through activation of the integrated stress response. Sci Transl Med. 2019;11:eaax2863.

94. Lübbert M, Grishina O, Schmoor C, Schlenk RF, Jost E, Crysandt $\mathrm{M}$, et al. Valproate and retinoic acid in combination with decitabine in elderly nonfit patients with acute myeloid leukemia: results of a multicenter, randomized, $2 \times 2$, phase II trial. J Clin Oncol. 2020;38:257-70.

95. Cao Y, Liu Y, Shang L, Wei W, Shen Y, Gu Q, et al. Decitabine and all-trans retinoic acid synergistically exhibit cytotoxicity against elderly AML patients via miR-34a/MYCN axis. Biomed Pharmacother. 2020;125:109878.

96. Wu W, Lin Y, Xiang L, Dong W, Hua X, Ling Y, et al. Low-dose decitabine plus all-trans retinoic acid in patients with myeloid neoplasms ineligible for intensive chemotherapy. Ann Hematol. 2016;95:1051-7.

97. Thomas S, Schelker R, Klobuch S, Zaiss S, Troppmann M, Rehli $\mathrm{M}$, et al. Biomodulatory therapy induces complete molecular remission in chemorefractory acute myeloid leukemia. Haematologica 2015;100:e4-6.

98. Klobuch S, Steinberg T, Bruni E, Mirbeth C, Heilmeier B, Ghibelli L, et al. Biomodulatory treatment with azacitidine, alltrans retinoic acid and pioglitazone induces differentiation of primary aml blasts into neutrophil like cells capable of ROS production and phagocytosis. Front Pharm. 2018;9:1380. 
99. Issa JP, Garcia-Manero G, Huang X, Cortes J, Ravandi F, Jabbour E, et al. Results of phase 2 randomized study of lowdose decitabine with or without valproic acid in patients with myelodysplastic syndrome and acute myelogenous Leukemia. Cancer 2015;121:556-61.

100. Craddock CF, Houlton AE, Quek LS, Ferguson P, Gbandi E, Roberts $\mathrm{C}$, et al. Outcome of azacitidine therapy in acute myeloid leukemia is not improved by concurrent vorinostat therapy but is predicted by a diagnostic molecular signature. Clin Cancer Res. 2017;23:6430-40.

101. Daver N, Boddu P, Garcia-Manero G, Yadav SS, Sharma P, Allison $\mathbf{J}$, et al. Hypomethylating agents in combination with immune checkpoint inhibitors in acute myeloid leukemia and myelodysplastic syndromes. Leukemia. 2018;32:1094-105.

102. Sallman D, Al Malki M, Asch A, Lee D, Kambhampati S, Donnellan W, et al. The first-in-class anti-CD47 antibody magrolimab combined with azacitidine is well-tolerated and effective in MDS patients: phase 1b results. EHA Library. 2020;295007.

103. Medeiros BC, McCaul K, Kambhampati S, Pollyea DA, Kumar $\mathrm{R}$, Silverman LR, et al. Randomized study of continuous highdose lenalidomide, sequential azacitidine and lenalidomide, or azacitidine in persons 65 years and over with newly-diagnosed acute myeloid leukemia. Haematologica. 2018;103:101-6.

104. Sekeres MA, Othus M, List AF, Odenike O, Stone RM, Gore $\mathrm{SD}$, et al. Randomized phase II study of azacitidine alone or in combination with lenalidomide or with vorinostat in higher-risk myelodysplastic syndromes and chronic myelomonocytic leukemia: North American Intergroup Study SWOG S1117. J Clin Oncol. 2017;35:2745-53.

105. Roboz GJ, Mandrekar SJ, Desai P, Laumann K, Walker AR, Wang ES, et al. Randomized trial of 10 days of decitabine +/bortezomib in untreated older patients with AML: CALGB 11002 (Alliance). Blood Adv. 2018;2:3608-17.

106. Huls G, Chitu DA, Pabst T, Klein SK, Stussi G, Griskevicius L, et al. Ibrutinib added to 10-day decitabine for older patients with AML and higher risk MDS. Blood Adv. 2020;4:4267-77.

107. Yilmaz M, Kantarjian HM, Muftuoglu M, Kadia TM, Konopleva M, Borthakur G, et al. Quizartinib with decitabine $+/$ - venetoclax is highly active in patients (Pts) with FLT3-ITD mutated (mut) acute myeloid leukemia (AML): clinical report and Signaling Cytof Profiling from a Phase IB/II Trial. Blood. 2020;136:19-20.

108. DiNardo C, Schuh A, Stein E, Montesinos P, Wei A, de Botton $\mathrm{S}$, et al. Enasidenib plus azacitidine significantly improves complete remission and overall response rates versus azacitidine monotherapy in mutant-IDH2 newly diagnosed acute myeloid leukemia (ND-AML). EHA Library. 2020;294959.

109. DiNardo C, Lachowiez C, Borthakur G, Loghavi S, Zeng Z, Kadia T, et al. Phase Ib/II study of the IDH1-mutant inhibitor ivosidenib with the BCL2 inhibitor venetoclax +/- azacitidine in IDH1-mutated hematologic malignancies. EHA Library. 2020; 294963.

110. Cluzeau T, Sebert M, Rahmé R, Cuzzubo S, Walter-Petrich A, Lehmann-Che J, et al. APR-246 combined with azacitidine in TP53 mutated myelodysplastic syndromes (MDS) and acute myeloid leukemia. A phase 2 study by the Groupe Francophone des Myélodysplasies (GFM). EHA Library. 2020;295001.

111. Athuluri-Divakar SK, Vasquez-Del Carpio R, Dutta K, Baker SJ, Cosenza SC, Basu I, et al. A small molecule RAS-mimetic disrupts RAS association with effector proteins to block signaling. Cell. 2016;165:643-55.

112. Garcia-Manero G, Fenaux P, Al-Kali A, Baer MR, Sekeres MA, Roboz GJ, et al. Rigosertib versus best supportive care for patients with high-risk myelodysplastic syndromes after failure of hypomethylating drugs (ONTIME): a randomised, controlled, phase 3 trial. Lancet Oncol. 2016;17:496-508.
113. Navada SC, Garcia-Manero G, OdchimarReissig R, Pemmaraju $\mathrm{N}$, Alvarado $\mathrm{Y}$, Ohanian $\mathrm{MN}$, et al. Rigosertib in combination with azacitidine in patients with myelodysplastic syndromes or acute myeloid leukemia: results of a phase 1 study. Leuk Res. 2020;94:106369.

114. Sekeres MA, Watts J, Radinoff A, Sangerman MA, Cerrano M, Lopez PF, et al. Randomized phase 2 trial of pevonedistat plus azacitidine versus azacitidine for higher-risk MDS/CMML or low-blast AML. Leukemia. 2021. https://doi.org/10.1038/ s41375-021-01125-4.

115. Scandura JM, Roboz GJ, Moh M, Morawa E, Brenet F, Bose JR, et al. Phase 1 study of epigenetic priming with decitabine prior to standard induction chemotherapy for patients with AML. Blood. 2011;118:1472-80.

116. Caiado F, Maia-Silva D, Jardim C, Schmolka N, Carvalho T, Reforco $\mathrm{C}$, et al. Lineage tracing of acute myeloid leukemia reveals the impact of hypomethylating agents on chemoresistance selection. Nat Commun. 2019;10:4986.

117. Schroeder T, Czibere A, Platzbecker U, Bug G, Uharek L, Luft $\mathrm{T}$, et al. Azacitidine and donor lymphocyte infusions as first salvage therapy for relapse of AML or MDS after allogeneic stem cell transplantation. Leukemia. 2013;27:1229-35.

118. Steinmann J, Bertz H, Wäsch R, Marks R, Zeiser R, Bogatyreva $\mathrm{L}$, et al. 5-Azacytidine and DLI can induce long-term remissions in AML patients relapsed after allograft. Bone Marrow Transpl. 2015;50:690-5.

119. Stein EM, Walter RB, Erba HP, Fathi AT, Advani AS, Lancet JE, et al. A phase 1 trial of vadastuximab talirine as monotherapy in patients with CD33-positive acute myeloid leukemia. Blood. 2018;131:387-96.

120. Fathi AT, Erba HP, Lancet JE, Stein EM, Ravandi F, Faderl S, et al. A phase 1 trial of vadastuximab talirine combined with hypomethylating agents in patients with CD33-positive AML. Blood. 2018;132:1125-33.

121. Döhner H, Lübbert M, Fiedler W, Fouillard L, Haaland A, Brandwein JM, et al. Randomized, phase 2 trial of low-dose cytarabine with or without volasertib in AML patients not suitable for induction therapy. Blood. 2014;124:1426-33.

122. Li X, Zhang Y, Chen M, Mei Q, Liu Y, Feng K, et al. Increased IFNgamma $(+) \mathrm{T}$ cells are responsible for the clinical responses of low-dose DNA-demethylating agent decitabine antitumor therapy. Clin Cancer Res. 2017;23:6031-43.

123. Luo N, Nixon MJ, Gonzalez-Ericsson PI, Sanchez V, Opalenik $\mathrm{SR}$, Li $\mathrm{H}$, et al. DNA methyltransferase inhibition upregulates MHC-I to potentiate cytotoxic T lymphocyte responses in breast cancer. Nat Commun. 2018;9:248.

124. Fozza C, Corda G, Barraqueddu F, Virdis P, Contini S, Galleu A, et al. Azacitidine improves the T-cell repertoire in patients with myelodysplastic syndromes and acute myeloid leukemia with multilineage dysplasia. Leuk Res. 2015;39:957-63.

125. Cooper ML, Choi J, Karpova D, Vij K, Ritchey J, Schroeder MA, et al. Azacitidine mitigates graft-versus-host disease via differential effects on the proliferation of $\mathrm{T}$ effectors and natural regulatory T cells in vivo. J Immunol. 2017;198:3746-54.

126. Fagone P, Mazzon E, Chikovani T, Saraceno A, Mammana S, Colletti G, et al. Decitabine induces regulatory $\mathrm{T}$ cells, inhibits the production of IFN-gamma and IL-17 and exerts preventive and therapeutic efficacy in rodent experimental autoimmune neuritis. J Neuroimmunol. 2018;321:41-8.

127. Costantini B, Kordasti SY, Kulasekararaj AG, Jiang J, Seidl T, Abellan PP, et al. The effects of 5-azacytidine on the function and number of regulatory $\mathrm{T}$ cells and T-effectors in myelodysplastic syndrome. Haematologica 2013;98:1196-205.

128. Santourlidis S, Trompeter HI, Weinhold S, Eisermann B, Meyer KL, Wernet $P$, et al. Crucial role of DNA methylation in 
determination of clonally distributed killer cell Ig-like receptor expression patterns in NK cells. J Immunol. 2002;169:4253-61.

129. Gao XN, Lin J, Wang LL, Yu L. Demethylating treatment suppresses natural killer cell cytolytic activity. Mol Immunol. 2009;46:2064-70.

130. Frikeche J, Clavert A, Delaunay J, Brissot E, Gregoire M, Gaugler B, et al. Impact of the hypomethylating agent 5azacytidine on dendritic cells function. Exp Hematol. 2011;39: 1056-63.

131. Zhou J, Yao Y, Shen Q, Li G, Hu L, Zhang X. Demethylating agent decitabine disrupts tumor-induced immune tolerance by depleting myeloid-derived suppressor cells. J Cancer Res Clin Oncol. 2017;143:1371-80.

132. Boada M, Echarte L, Guillermo C, Diaz L, Tourino C, Grille S. 5-Azacytidine restores interleukin 6-increased production in mesenchymal stromal cells from myelodysplastic patients. Hematol Transfus Cell Ther. 2020. https://doi.org/10.1016/j.htct. 2019.12.002.

133. Lee S, Kim HS, Roh KH, Lee BC, Shin TH, Yoo JM, et al. DNA methyltransferase inhibition accelerates the immunomodulation and migration of human mesenchymal stem cells. Sci Rep. 2015;5:8020. 